\title{
Analysis of 3D Printed Diopside Scaffolds Properties for Tissue Engineering
}

\author{
Tingting LIU ${ }^{1}$, Youwen DENG ${ }^{3}$, Chengde GAO ${ }^{1}$, Pei FENG ${ }^{1}$, Cijun SHUAI ${ }^{1, *}$, \\ Shuping PENG ${ }^{2,4}$
}

\author{
${ }^{1}$ State Key Laboratory of High Performance Complex Manufacturing, Central South University, No. 932, South Lushan \\ Road, Changsha, Hunan, P. R. China \\ ${ }^{2}$ School of Basic Medical Science, Central South University, No.172, Tongzipo Road, Changsha, Hunan, P.R. China \\ ${ }^{3}$ Department of Spine Surgery of the Second Xiangya Hospital, Central South University, No.139, Renmin Middle Road, \\ Changsha, Hunan, P.R. China \\ ${ }^{4}$ Hunan Provincial Tumor Hospital and the Affiliated Tumor Hospital of Xiangya School of Medicine, Central South \\ University, No.283, Tongzipo Road, Changsha, Hunan, P.R. China
}

cross $^{\text {ref }}$ http://dx.doi.org/10.5755/j01.ms.21.4.9845

Received 13 February 2015; accepted 19 June 2015

\begin{abstract}
Diopside exhibits favorable potential for bone repair on account of the good mechanical performance, bioactivity and biocompatibility. In this paper, diopside scaffolds with high pore interconnectivity were successfully fabricated by laser three-dimensional (3D) printing. The microstructure and mechanical performance of the diopside scaffolds were studied. The experimental analysis indicated that diopside particles gradually fused together until a dense structure was built with an energy density increasing in the range between 2.4 and $4.8 \mathrm{~J} \cdot \mathrm{mm}^{-2}$. Meanwhile, compressive strength and fracture toughness increased gradually from $5.96 \pm 0.88 \mathrm{MPa}$ to $10.87 \pm 0.55 \mathrm{MPa}$. However, mechanical properties decreased due to the appearance of voids when energy density were 5.4 and $6 \mathrm{~J} \cdot \mathrm{mm}^{-2}$. Simulated body fluid (SBF) tests showed that apatite crystals formed on the diopside scaffolds surface, and the apatite crystals increased with soaking time. Cell culture tests indicated the scaffolds supported the adhesion and growth of MG-63 cells. The study suggested that diopside scaffolds fabricated by laser 3D printing are promising candidates for bone tissue engineering. Keywords: diopside, scaffold, laser 3D printing, bone tissue engineering.
\end{abstract}

\section{INTRODUCTION}

The requirement for the substitutes to replace injured or diseased bone tissue has greatly increased in recent years $[1,2]$. Diopside $\left(\mathrm{CaMgSi}_{2} \mathrm{O}_{6}\right)$ is a kind of silicabased ceramics with high bending strength and fracture toughness [3]. Moreover, $\mathrm{Si}$ and $\mathrm{Mg}$ elements released from diopside were favorable for the cells growth and proliferation [4-6]. Ghorbanian et al. prepared diopside/silk fibroin nanocomposite scaffolds using freezedrying method and investigated their application for maxillofacial bone regeneration [7]. $\mathrm{Wu} \mathrm{C}$. et al. researched the physicochemical and biological performance of diopside scaffolds prepared by polymer sponge template method [3].

However, these methods cannot precisely achieve pore shape, pore interconnectivity and internal structure of the diopside scaffolds $[8,9]$. These characteristics are essential for growth of bone tissues and transport of nutrients and waste products [10].

Selective laser sintering technology (SLS) is a laser 3D printing method that can fabricate the parts with complex external shape and controllable spatial structures. Its manufacturing method is that a diopside powder layer is spread then fused by a laser beam. After a diopside layer is sintered, another powder layer is spread above the former layer and repeat the process to complete the sintering parts

\footnotetext{
* Corresponding authors. Tel.: +86731 88879351; fax: +8673188879044. E-mail address: shuai@mail.csu.edu.cn (C.Shuai)
}

[11]. This provides a good method for manufacturing controllable porous structure of scaffolds.

This study aimed to fabricate diopside scaffolds by SLS and focus on the effects of energy density on mechanical properties and microstructure. The fracture toughness is tested with digital micro-hardness tester and the compressive strength is tested with universal testing machine. The composition is examined with XRD and the microstructure is examined with SEM. Moreover, the bioactivity of diopside scaffolds is investigated in SBF and the biocompatibility is investigated in vitro.

\section{EXPERIMENTAL DETAILS}

\subsection{Material and processing}

Diopside (Calcium oxide, 24 mass \%; Silicon dioxide, 55 mass \%; Magnesium oxide, 18 mass \%), is purchased from Chinese Technology New Materials (Kun Shan) Co., Ltd. Its melting temperature is $1300{ }^{\circ} \mathrm{C}$ and the particle size ranges from 10 to $100 \mu \mathrm{m}$. Diopside scaffolds were constructed by a home-made SLS system [12]. The scaffolds were sintered under different laser energy densities $\left(2.4,3.6,4.8,5.4,6 \mathrm{~J} / \mathrm{mm}^{-2}\right)$, and other parameters remained unchanged (scan spacing $2 \mathrm{~mm}$, laser spot diameter $0.8 \mathrm{~mm}$, scanning rate $100 \mathrm{~mm} / \mathrm{min}$ and powder layer $0.2 \mathrm{~mm}$ ). When the diopside scaffolds were completed, they were cooled without temperature control. Then the excess powder was removed. The energy density (ED) was evaluated according to [13]:

$E D=E /(d . v)$, 
where $E$ is the laser power, $d$ is spot diameter, $v$ is scanning rate.

\subsection{Scaffold fabrication}

In the process of SLS, the powder was paved on the working platform. The powder layer was selectively sintered by the laser beam and bonded to form a solid layer. Then the working platform was moved down by the thickness of a layer and a new layer of powder was spread on the sintered part. The steps were repeated until the completion of the three-dimensional scaffolds. The sintering process was performed at power of $6.5 \mathrm{~W}$, scanning speed of $100 \mathrm{~mm} / \mathrm{min}$, spot diameter of $1.2 \mathrm{~mm}$, scan spacing of $2.0 \mathrm{~mm}$ and layer thickness of about $0.1 \mathrm{~mm}$. The porous scaffold was fabricated under the optimal $E D$ of $4.8 \mathrm{~J} / \mathrm{mm}^{2}$ (Fig. 1). The dimension of the diopside scaffold is $15.5 \times 15.5 \times 7 \mathrm{~mm}^{3}$ and the pore size is $1 \mathrm{~mm}$. The scaffold consisted of six struts per layer with $1 \mathrm{~mm}$ in width and $1.5 \mathrm{~mm}$ in thickness.
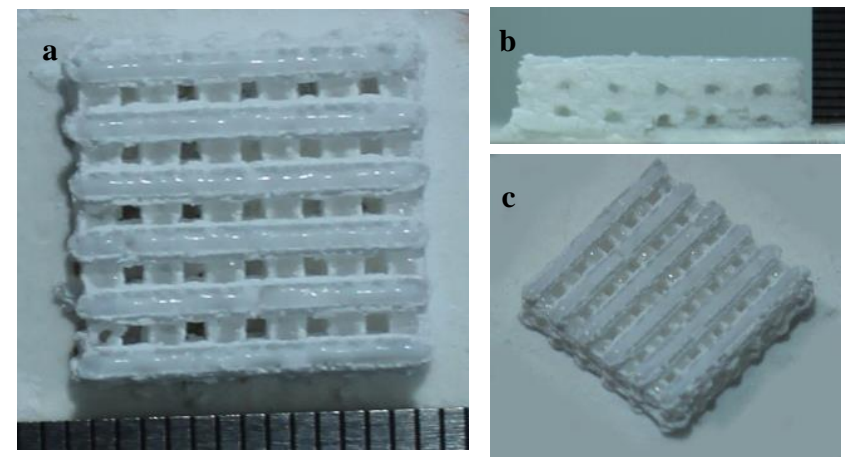

Fig. 1. The interconnected porous diopside scaffold with interconnected pores fabricated by laser sintering: $\mathrm{a}$-overhead view; $\mathrm{b}$ - side view; $\mathrm{c}$ - overview

\subsection{Characterization}

\subsubsection{Microstructures}

The microstructure of diopside scaffold was examined using SEM, with a MIRA 3 LMU (TESCAN, Czech Republic) at the acceleration voltage of $20 \mathrm{KV}$. Before the observation, the scaffold was pre-coated with gold/palladium in inert atmosphere (argon gas) (JEOL, JFC-1600 Auto Fine Coater, Japan).

The phase compositions were identified using XRD, with a D8 Advance diffractometer (Bruker AXS, Karlsruhe, Germany) based on CuKa radiation. The scan step was applied at $2 \theta$ in the range between 10 and $70^{\circ}$ at $1 \%$ min. Then diopside scaffold was ground to powders prior to the observation.

\subsubsection{Mechanical properties}

The compressive properties of the diopside scaffolds were tested by an electronic universal testing machine (Microcomputer control) with a rate of $8 \mu \mathrm{m} / \mathrm{s}$. The fracture toughness of the diopside scaffolds was determined using a digital micro-hardness tester (Model: HXD-1000TM/LCD, Taiming Optical Instrument Co., Shanghai) at $500 \mathrm{gf}$ load. Before fracture toughness tests, the diopside scaffolds were ground and polished stage by stage with 800-grit, 1200-grit and 1500-grit diamond papers under water lubrication. The mechanical performances were achieved from six tests. All data were showed as the means \pm S.E. (Standard error). to $[14]$ :

The fracture toughness $\left(K_{I C}\right)$ was calculated according

$K_{I C}=0.0824\left(F / L^{3 / 2}\right)$,

where $L$ is the radial crack length, $F$ is applied load.

\subsubsection{Apatite crystals in SBF}

The diopside scaffolds were immersed in SBF to evaluate apatite-forming ability. SBF was formed following the method established by Kokubo and Takadama [15], which had a similar ionic composition in human blood plasma. The immersion time of the diopside scaffolds in SBF was 14, 21 and 28 days at $37^{\circ} \mathrm{C}$, respectively, changing the solution every three days. The diopside scaffolds were subsequently taken out from the solution at preset soaking time, washing in distilled water, and then drying at vacuum drying oven. The apatite crystals on the scaffolds surface were studied using SEM equipped with EDS (Neptune XM4, EDAX Inc., USA).

\subsubsection{Cell culture}

MG-63 cells supplied by the American Type Culture Collection in Rockville, Md. were used in this research. MG-63 isolated from human osteosarcoma was chosen because they could express a number of characteristic features of osteoblasts [16]. The cells were kept with Dulbecco's modified Eagle's medium (Gibco, Germany) containing $10 \%(\mathrm{v} / \mathrm{v})$ fetal calf serum (Gibco-RBL Life Technologies Ltd, Paisley, United Kingdom), 100 units/ml penicillin, $100 \mathrm{mg} / \mathrm{ml}$ streptomycin at $37{ }^{\circ} \mathrm{C}$. The diopside scaffolds were disinfected by immersion in $70 \%$ ethanol prior to seeding cells. MG-63 cells were seeded into the diopside scaffolds at an initial concentration of $4 \times 10^{5}$ cells $/ \mathrm{cm}^{2}$. Subsequently, the scaffold/cell construct was placed into 24 -well plates and cultured in a humidified incubator at 37 degrees centigrade for 7 days. After the cell culture, the scaffold was taken out from the plates, and then washed with PBS solution. Sequentially, the diopside scaffolds were fastened with $4 \%$ sucrose, $4 \%$ paraformaldehyde and $2.5 \%$ glutaraldehyde in PBS for $30 \mathrm{~min}$. Then the diopside scaffolds were dehydrated with a graded ethanol $(30-100 \%)$ and coated with gold in a vacuum followed by an examination with SEM.

\section{RESULTS AND DISCUSSION}

\subsection{SEM analysis}

The microstructure of the diopside scaffolds sintered under different energy densities is shown in Fig. $1 \mathrm{a}-\mathrm{d}$. Only a few diopside particles fused and connected together at a low $E D$ of $2.4 \mathrm{~J} / \mathrm{mm}^{2}$ (Fig. 2 a). When $E D$ increased to $3.6 \mathrm{~J} / \mathrm{mm}^{2}$, the microstructure became well during sintering (Fig. 2 b). And it had a much high density at $E D$ of $4.8 \mathrm{~J} / \mathrm{mm}^{2}$ (Fig. $2 \mathrm{c}$ ). However, some voids formed as $E D$ further increased to $6 \mathrm{~J} / \mathrm{mm}^{2}$ (Fig. $2 \mathrm{~d}$ ). It might be ascribed to the rapid temperature change, which inhibited the gas coming out during the sintering process. 


\subsection{XRD analysis}

XRD analysis was performed to investigate the phase compositions of diopside before and after sintering. The peaks of initial diopside powder (Fig. 2 e) were in accordance with the standard card (No. 190239) of diopside. There were similar XRD patterns among the diopside scaffolds at all energy densities, therefore the pattern of scaffold at $E D$ of $4.8 \mathrm{~J} / \mathrm{mm}^{2}$ is shown in Fig. $1 \mathrm{f}$. It showed that the degree of crystallinity changed but no new phases formed after sintering.
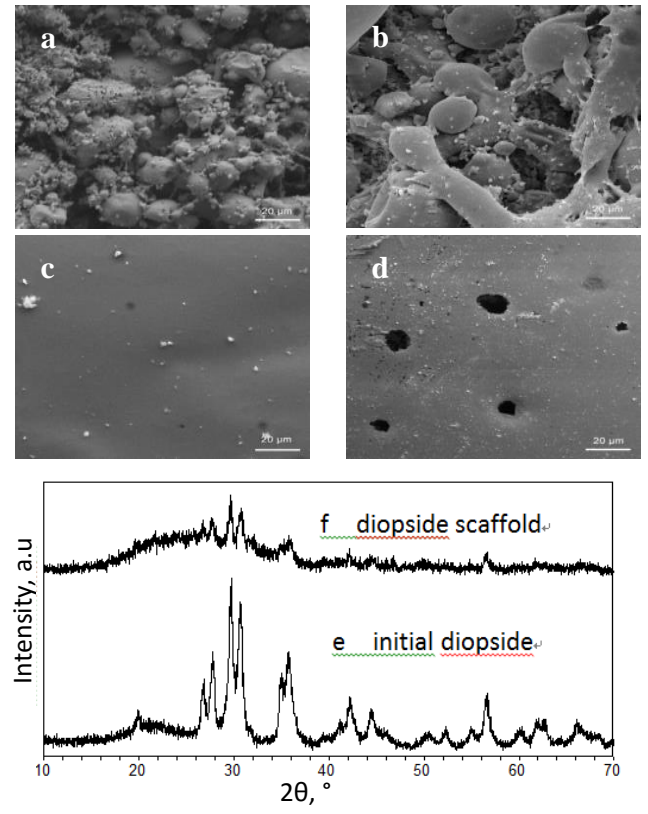

Fig. 2. SEM micrograph of diopside scaffolds sintered at different $E D: \mathrm{a}-2.4 \mathrm{~J} / \mathrm{mm}^{2} ; \mathrm{b}-3.6 \mathrm{~J} / \mathrm{mm}^{2} ; \mathrm{c}-4.8 \mathrm{~J} / \mathrm{mm}^{2}$; $\mathrm{d}-6 \mathrm{~J} / \mathrm{mm}^{2}$; XRD patterns: e-initial diopside powder; f-diopside scaffold sintered at $E D$ of $4.8 \mathrm{~J} / \mathrm{mm}^{2}$

\subsection{Mechanical performance}

The effects of $E D\left(3.6,4.2,4.8,5.4,6 \mathrm{~J} / \mathrm{mm}^{2}\right)$ on mechanical performance (compressive strength and fracture toughness) was investigated (Fig. 3). Compressive strength of the diopside scaffolds was $5.96 \pm 0.88 \mathrm{MPa}$ at $E D$ of $3.6 \mathrm{~J} / \mathrm{mm}^{2}$, and then increased significantly when $E D$ was increased. The compressive strength reached the maximum $(10.87 \pm 0.55 \mathrm{MPa})$ at $E D$ of $4.8 \mathrm{~J} / \mathrm{mm}^{2}$. The improvement of densification of the scaffold was responsible for the increasing compressive strength. However, further increase in the energy density led to a slight reduction in compressive strength, which was attributed to the emergence of voids. In addition, the variation of fracture toughness showed trend, similar to that of compressive strength. The optimal fracture toughness was $3.10 \pm 0.22 \mathrm{MPa} \cdot \mathrm{m}^{1 / 2}$. The compressive property was much greater than that of trabecular bone (range from 0.1 to $16 \mathrm{MPa}$ ) [17], and fracture toughness was comparable to that of human cortical bone $\left(2-12 \mathrm{MPa} \cdot \mathrm{m}^{1 / 2}\right)$ [18]. Compressive strength of the diopside scaffolds fabricated by $\mathrm{Wu} \mathrm{C}$. et al [3] via polymer sponge template method was $1.36 \pm 0.37 \mathrm{MPa}$. It was much lower than compressive strength of the diopside scaffolds prepared by us. Chen et al. calcination diopside in a box furnace, and the scaffolds exhibited the compressive strength of $0.27 \mathrm{MPa}$, which was lower than the scaffolds prepared by us [19]. Nonami et al. prepared diopside ceramic by sintering a powder compact composing of $\mathrm{CaO}-\mathrm{MgO}-2 \mathrm{SiO}_{2}$ at $1300{ }^{\circ} \mathrm{C}$ [20]. The fracture toughness was $3.50 \mathrm{MPa} \cdot \mathrm{m}^{1 / 2}$, which was close to that of the scaffolds prepared by us.

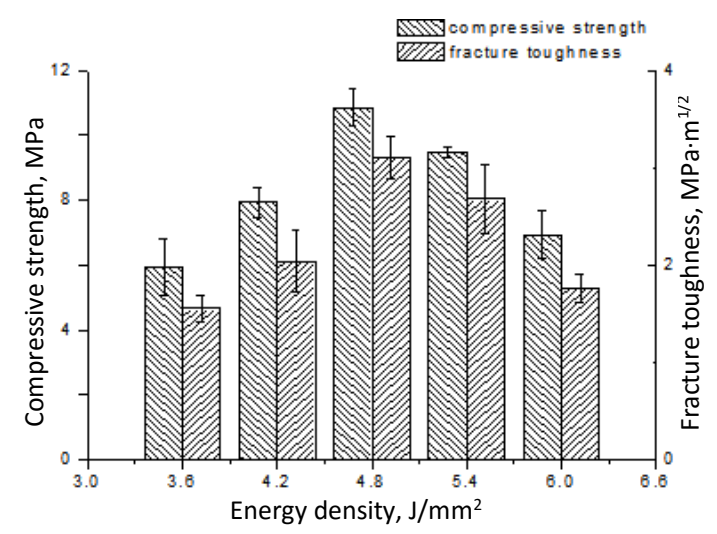

Fig. 3. The relationship between energy density and mechanical performance of the diopside scaffolds

\subsection{Bioactivity evaluation}

The scaffolds fabricated under $E D$ of $4.8 \mathrm{~J} / \mathrm{mm}^{2}$ were immersed in SBF, and the SEM micrographs are shown in Fig. 4 from a to d. After 14 days soaking, small globular crystals with the diameter size of about $3 \mu \mathrm{m}$ were deposited on the scaffold surface (Fig. 4 a).
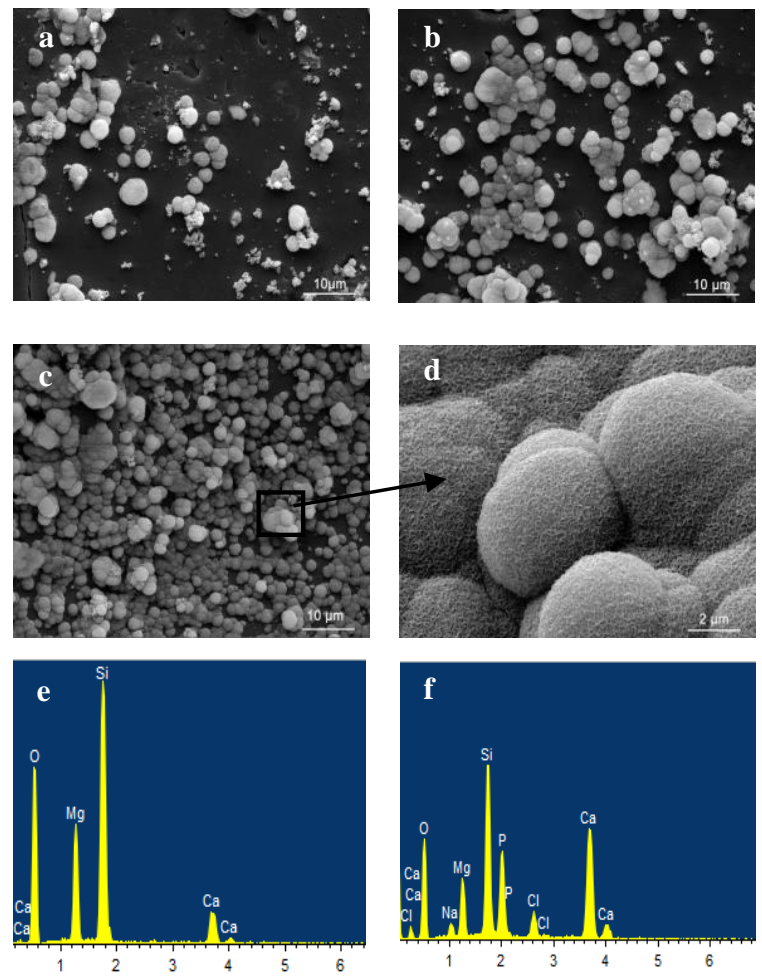

Fig. 4. The crystals on the surface of diopside scaffolds over various immersion time: $a-14$ days; $b-21$ days; $c-$ 28 days; $d$-crystals at high-magnification; EDS spectra of the diopside scaffolds before (e) and after (f) immersing in SBF

The amount of the crystals grew gradually with the increasing immersion time in SBF (Fig. 4 b). After 28 
days, the surface was completely covered with globular crystal (Fig. 4 c). High-magnification SEM revealed that the globular crystals were sponge-like (Fig. 4 d). EDS spectrum for the diopside scaffold before and after SBF immersion are shown in Fig. 4 e and f. There were $\mathrm{Ca}, \mathrm{Mg}$, $\mathrm{Si}$ and $\mathrm{O}$ element before immersing in SBF, which was consistent with the composition of diopside. However, $\mathrm{P}$, $\mathrm{Cl}$, Na appeared in EDS spectra after immersing. $\mathrm{Ca} / \mathrm{P}$ ratio calculated from EDS was 1.68, which was close to that of hydroxyapatite. Research has established that one of the major characteristics of biomaterials is inducing the formation of hydroxyapatite that has the same chemical composition to that of the human bone. In the present study, the bioactivity analysis showed that apatite crystals were formed and deposited on the diopside scaffold surface, indicating excellent bioactivity of diopside scaffolds.

\subsection{Cell behavior}

The biocompatibility is another significant characteristic of bioactive materials, and it can be evaluated by the cell adhesion, proliferation, and spreading. In this study, MG-63 cells were seeded on the diopside scaffold surface for 7 days, and the cell morphology was shown in Fig. 5. The adhered cells exhibited an elongated, spindle-shaped appearance, which was typical for osteoblast-like cells. Moreover, extracellular matrix secreted by MG-63 cells grew on diopside scaffold surface, which indicated high cell activity on the diopside scaffold. The results indicated that the scaffolds prepared by SLS supported the adhesion and spreading of MG-63 cells.

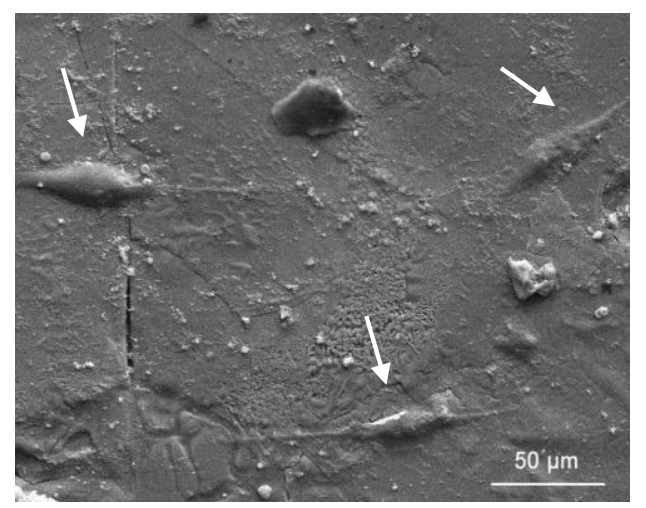

Fig. 5. SEM micrograph of diopside scaffold seeded with MG-63 cells for 7 days

\section{CONCLUSIONS}

Porous diopside scaffolds were successfully fabricated by SLS. In this study, the fabricated scaffolds possessed 3D pore structures and large surface areas to provide good conditions for cell adhesion and the exchange of nutrients through the scaffolds. The scaffolds presented excellent mechanical properties, which has the highest compressive strength at 10.87 (SD 0.55) MPa and fracture toughness at 3.10 (SD 0.22) $\mathrm{MPa} \cdot \mathrm{m}^{1 / 2}$. Additionally, the scaffolds exhibited good bioactivity, which could induce apatite layer formation on the surfaces after immersion in SBF solution. Cell experiment showed the diopside scaffolds facilitated the MG-63 cell adhesion and growth, suggesting good biocompatibility. The results suggested that diopside scaffolds fabricated by SLS had a good potential in the field of bone regeneration.

\section{Acknowledgements}

The authors thank the Natural Science Foundation of China (Nos. 81428018, 81472058, and 51222506), High Technology Research and Development Program of China (No. 2015AA033503) for providing the research grant.

\section{REFERENCES}

1. Jiang, D.M., Cao, Z.Y., Sun, X., Guo, L., Liu, J.G. Effect of Yttrium Addition on Microstructure and Mechanical Properties of $\mathrm{Mg}-\mathrm{Zn}-\mathrm{Ca}$ Alloy Materials Research Innovations 17 (s1) 2013: pp. 33-38. http://dx.doi.org/10.1179/1432891713Z.000000000194

2. Shuai, C., Deng, J., Li, P., Peng, S. Novel Forsterite Scaffolds for Bone Tissue Engineering: Selective Laser Sintering Fabrication and Characterization Materials Research Innovations 18 (s2) 2014: pp. 74-78.

3. Wu, C., Ramaswamy, Y., Zreiqat, H. Porous Diopside (Camgsi206) Scaffold: A Promising Bioactive Material for Bone Tissue Engineering Acta biomaterialia 6 (6) 2010: pp. 2237-2245.

4. Shuai, C., Liu, T., Gao, C., Feng, P., Peng, S. Mechanical Reinforcement of Diopside Bone Scaffolds with Carbon Nanotubes International Journal of Molecular Sciences 15 (10) 2014: pp. 19319-19329.

5. Lu, J., Wei, J., Gan, Q., Lu, X., Hou, J., Song, W., Yan, Y., Ma, J., Guo, H., Xiao, T., Liu, C. Preparation, Bioactivity, Degradability And Primary Cell Responses To An Ordered Mesoporous Magnesium-Calcium Silicate Microporous and Mesoporous Materials 163 2012: pp. $221-228$.

http://dx.doi.org/10.1016/j.micromeso.2012.06.037

6. Feng, P., Deng, Y., Duan, S., Gao, C., Shuai, C., Peng, S. Liquid Phase Sintered Ceramic Bone Scaffolds by Combined Laser And Furnace International Journal of Molecular Sciences $15(8) \quad 2014$ : pp. 14574-14590. http://dx.doi.org/10.3390/ijms150814574

7. Ghorbanian, L., Emadi, R., Razavi, S., Shin, H., Teimouri, A. Fabrication And Characterization Of Novel Diopside/Silk Fibroin Nanocomposite Scaffolds For Potential Application In Maxillofacial Bone Regeneration International journal of biological macromolecules 58 2013: pp. $275-280$. http://dx.doi.org/10.1016/j.ijbiomac.2013.04.004

8. Feng, P., Niu, M., Gao, C., Peng, S., Shuai, C. A Novel Two-Step Sintering for Nano-Hydroxyapatite Scaffolds For Bone Tissue Engineering Scientific reports 4 2014: pp. 5599. http://dx.doi.org/10.1038/srep05599

9. Yeong, W.Y., $\quad$ Chua, C.K., Leong, K.F., Chandrasekaran, M. Rapid Prototyping in Tissue Engineering: Challenges and Potential Trends in biotechnology 22 (12) 2004: pp. 643-652. http://dx.doi.org/10.1016/j.tibtech.2004.10.004

10. Zhou, J., Cao, C., Ma, X. A Novel Three-Dimensional Tubular Scaffold Prepared from Silk Fibroin by Electrospinning International journal of biological macromolecules 45 (5) 2009: pp. 504-510.

11. Liu, H., Fan, Z., Huang, N., Dong, X. A Note on Rapid Manufacturing Process of Metallic Parts Based on SLS 
Plastic Prototype Journal of materials processing technology 142 (3) 2003: pp. 710-713.

http://dx.doi.org/10.1016/S0924-0136(03)00811-2

12. Shuai, C., Gao, C., Nie, Y., Hu, H., Zhou, Y., Peng, S. Structure and Properties of Nano-Hydroxypatite Scaffolds for Bone Tissue Engineering with A Selective Laser Sintering System Nanotechnology $22(28)$ 2011: pp. 285703.

13. Salmoria, G. V., Klauss, P., Paggi, R. A., Kanis, L. A., Lago, A. Structure and Mechanical Properties of Cellulose Based Scaffolds Fabricated by Selective Laser Sintering Polymer Testing 28 (6) 2009: pp. 648-652.

14. Han. W. Glass Ceramic Of High Hardness And Fracture Toughness Developed From Iron-Rich Wastes Acta Metallurgica Sinica (English Letters) 22(3) 2009: pp. $181-190$.

15. Kokubo, T., Takadama, H. How Useful Is SBF in Predicting in Vivo Bone Bioactivity? Biomaterials 27 (15) 2006: pp. 2907-2915. http://dx.doi.org/10.1016/j.biomaterials.2006.01.017

16. Li, Z., Ramay, H. R., Hauch, K. D., Xiao, D., Zhang, M. Chitosan-Alginate Hybrid Scaffolds for Bone Tissue Engineering Biomaterials $26(18)$ 2005: pp. 3919-3928.
17. Shuai, C., Feng, P., Yang, B., Cao, Y., Min, A., Peng, S. Effect of Nano-Zirconia on The Mechanical And Biological Properties of Calcium Silicate Scaffolds International Journal of Applied Ceramic Technology 2014 (In press) http://dx.doi.org/10.1111/ijac.12337

18. Ramesh, S., Tan, C. Y., Sopyan, I., Hamdi, M., Teng, W. D. Consolidation if Nanocrystalline Hydroxyapatite Powder Science and Technology of Advanced Materials 8 (1) 2007: pp. 124-130. http://dx.doi.org/10.1016/j.stam.2006.11.002

19. Chen, C., Watkins-Curry, P., Smoak, M., Hogan, K., Deese, S., McCandless, G.T., Chan, J.Y., Hayes, D.J. Targeting Calcium Magnesium Silicates for Polycapralactone/Ceramic Composite Scaffolds ACS Biomaterials Science \& Engineering 1(2) 2015: pp. $94-102$.

20. Nonami, T., Tsutsumi, S. Study of Diopside Ceramics for Biomaterials Journal of Materials Science: Materials in Medicine 10 (8) 1999: pp. 475-479. http://dx.doi.org/10.1023/A:1008996908797 